\title{
Perioperative Complications after Radical Prostatectomy: Open versus Robot-Assisted Laparoscopic Approach
}

\author{
Michael Froehner ${ }^{\mathrm{a}}$ Vladimir Novotny $^{\mathrm{a}}$ Rainer Koch $^{\mathrm{b}}$ Steffen Leike ${ }^{\mathrm{a}}$ \\ Lars Twelker $^{\mathrm{a}}$ Manfred P. Wirth ${ }^{\mathrm{a}}$ \\ Departments of a Urology and b Medical Statistics and Biometry, University Hospital 'Carl Gustav Carus', \\ Dresden University of Technology, Dresden, Germany
}

\section{Key Words}

Health service research · Complications · Radical prostatectomy $\cdot$ Lymphoceles $\cdot$ Blood transfusion

\begin{abstract}
Background: The best technique of radical prostatectomy - open versus robot-assisted approach - is controversially discussed. In this study, we compared the complication rates of open and robot-assisted radical prostatectomy during the introduction and subsequent routine use of a da Vinci ${ }^{\circledR}$ robotic device while open surgery remained the standard approach. Patients and Methods: Between January 1st, 2006, and June 4th, 2012, 2,754 men underwent radical prostatectomy at our department. Among them, 317 received robotassisted and 2,438 open surgery. According to the requirements for prostate cancer centers certified by the Deutsche Krebsgesellschaft (German Cancer Society), a prospective database recording perioperative complications was built up. The complication rates of open and robot-assisted radical prostatectomy were compared with the $x^{2}$ or Fisher exact test. The distributions of quantitative variables were compared with $U$ tests. Results: Whereas the demographic factors favored patients selected for robot-assisted radical prostatectomy, there were no differences between open and robot-assisted surgery concerning length of stay, autologous
\end{abstract}

blood transfusion rates and the incidence of perioperative complications. Conclusions: Open and robot-assisted radical prostatectomy had comparable complication rates. With better patient- and tumor-related parameters as well as decreasing transfusion rates in the robot-assisted subgroup, this observation might reflect the learning curves of the involved robotic surgeons.

Copyright $\odot 2013$ S. Karger AG, Basel

\section{Introduction}

Controversies surround the choice of surgical technique in candidates for radical prostatectomy [1-3]. In a recently published meta-analysis, robot-assisted radical prostatectomy was associated with decreased blood loss, whereas the other complications did not differ meaningfully [4]. In this study, we used data on perioperative complications collected fulfilling the requirements for prostate cancer centers certified by the Deutsche Krebsgesellschaft (German Cancer Society) to compare the safety of open retropubic and robot-assisted radical prostatectomy during introduction and routine use of a da Vinci ${ }^{\circledR}$ robotic device with open surgery remaining the standard approach.

\section{KARGER}

E-Mail karger@karger.com

www.karger.com/uin
(C) 2013 S. Karger AG, Basel

0042-1138/13/0903-0312\$38.00/0 


\section{Patients and Methods}

Between January 1st, 2006, and June 4th, 2012, 2,754 men underwent radical prostatectomy at our department. Among them, 317 received robot-assisted and 2,438 open surgery. All robot-assisted procedures were performed with the 3-arm da Vinci robotic device. Open surgery was performed with one exception (perineal incision) via the retropubic approach. Demographic data are given in table 1 . The mean PSA in patients without neoadjuvant hormonal treatment was $9.4 \mathrm{ng} / \mathrm{ml}$. $71 \%$ of patients had organ confined node-negative disease. In patients who underwent pelvic lymph node dissection, the mean number of retrieved lymph nodes was 15 . During radical prostatectomy, the dorsal vain complex was transected and sutured afterwards. In the case of nerve sparing, coagulation of the nerve bundles was avoided.

During the recruitment period of this study, 3 of the 7 involved surgeons performed their 100th radical prostatectomy, the other 4 had already greater experience at the beginning of recruitment. After receiving the certificate at a prostate cancer center in December 2007, all radical prostatectomies were performed by surgeons with an experience of more than 100 radical prostatectomies or under surveillance of a surgeon with an experience of more than 100 such procedures. In the time period in question, the latter fitted to one surgeon. At our department, the da Vinci robotic device (Intuitive Surgical Systems, Inc.) was introduced in March 2006. Robot-assisted surgery was offered to patients in good general condition with appropriately favorable tumor parameters without, however, using strictly defined thresholds. Open retropubic radical prostatectomy remained the standard procedure. During the recruitment period of this study, 5 surgeons performed both open and robot-assisted radical prostatectomy whereas three performed only open radical prostatectomy. The complication database was built up for quality assurance purposes. It was used to document the complication rates according to the requirements for prostate cancer centers certified by the Deutsche Krebsgesellschaft (German Cancer Society). Complications were identified by chart review by a documentation assistant who undertook this review after initial instruction and surveillance by an urologist. The following categories were recorded: length of stay, homologous blood transfusions, lymphocele, lymphocele requiring treatment, deep vein thrombosis, lung embolus, wound infection, relaparotomy or secondary suture, acute myocardial infarction, death within 30 days after surgery. Comparisons of were made with the chi square or Fisher exact test. The distributions of quantitative variables were compared with $U$ tests. The statistical analyses were performed with the Statistical Analysis Systems (SAS Institute, Cary, N.C., USA) statistical package.

\section{Results}

The demographic data differed between the two surgical techniques with patients selected for robot-assisted radical prostatectomy having had the better clinical and tumor-related parameters (table 1). Patients selected for robot-assisted surgery had lower PSA values, were younger and healthier (less patients were classified as
Table 1. Demographic data of the patient sample stratified by surgical technique

\begin{tabular}{lccr}
\hline Criterion & Open & $\begin{array}{l}\text { Robot- } \\
\text { assisted }\end{array}$ & $\mathrm{p}$ \\
\hline ASA 3 & $281(16.1)$ & $24(8.9)$ & 0.0022 \\
Organ-confined tumor* & $1,597(65.5)$ & $241(76.0)$ & 0.0002 \\
Lymphadenectomy performed & $2,324(95.4)$ & $290(91.5)$ & 0.0031 \\
If done: mean number of nodes & 15 & 13 & $<0.0001$ \\
PSA, ng/ml (mean values**) & 10.4 & 6.4 & $<0.0001$ \\
Age, years (mean values) & 64.9 & 62.6 & $<0.0001$ \\
\hline
\end{tabular}

Figures in parentheses are percentages.

* pT2 and node-negative; ${ }^{* *}$ of patients without neoadjuvant hormonal treatment.

Table 2. Comparison of complications and related outcome parameters between open and robot-assisted radical prostatectomy

\begin{tabular}{|c|c|c|c|}
\hline Complication/criterion & $\begin{array}{l}\text { Open } \\
(\mathrm{n}=2,437)\end{array}$ & $\begin{array}{l}\text { Robot- } \\
\text { assisted } \\
(\mathrm{n}=317)\end{array}$ & $\mathrm{p}$ \\
\hline Length of stay (mean value) & 7.7 days & 8.0 days & 0.71 \\
\hline $\begin{array}{l}\text { Homologous blood transfusions, } \\
\text { n patients }\end{array}$ & $182(10.4)$ & $24(8.9)$ & 0.45 \\
\hline Any lymphocele diagnosed & $636(26.1)$ & $98(30.9)$ & 0.07 \\
\hline Lymphocele, treated & $119(4.9)$ & $15(4.7)$ & 0.91 \\
\hline Deep vein thrombosis & $57(2.3)$ & $7(2.2)$ & 0.88 \\
\hline Lung embolus & $15(0.6)$ & $1(0.3)$ & 0.51 \\
\hline Wound infection & $77(3.2)$ & $8(2.5)$ & 0.54 \\
\hline Relaparotomy or secondary suture & $15(0.9)$ & $2(0.7)$ & 1.00 \\
\hline Acute myocardial infarction & $1(0.04)$ & $1(0.3)$ & 0.22 \\
\hline $\begin{array}{l}\text { Death within } 30 \text { days } \\
\text { postoperatively }\end{array}$ & $1(0.04)$ & $1(0.3)$ & 0.22 \\
\hline Serious complications* & $90(3.7)$ & $10(3.2)$ & 0.63 \\
\hline Any complication** & $508(29.1)$ & $89(33.0)$ & 0.20 \\
\hline
\end{tabular}

Figures in parentheses are percentages.

* Deep vein thrombosis, lung embolus, acute myocardial infarction, death within 30 days postoperatively; ${ }^{* *}$ lymphocele, deep vein thrombosis, lung embolus, wound infection, relaparotomy or secondary suture, acute myocardial infarction or death within 30 days postoperatively.
American Society of Anesthesiologists physical status class 3 ). If lymph node dissection was performed, the mean number of retrieved nodes was something higher in patients who underwent open surgery (table 1). The comparison of the lengths of stay, transfusion and complication rates are given in table 2 . Two deaths within 30 days after surgery occurred, one after a postoperative acute myocardial infarction, the other suddenly after al- 
ready being discharged from the hospital. There were no significant differences between open and robot-assisted surgery in this study concerning these parameters. The only category with something like a trend towards a difference was overall lymphocele formation rate, where robot-assisted surgery was associated with a marginally higher rate.

\section{Discussion}

With the exception of the autologous blood transfusion rates - that have been reported to be lower in patients undergoing robot-assisted radical prostatectomy [4] but did not differ between the two surgical techniques in this series - this study confirms the results of the recently published meta-analysis that showed comparable complication rates of open and robot-assisted radical prostatectomy [4]. The incidence of lymphocele formation after radical prostatectomy differs widely according to different surgical techniques and diagnostic effort. Performing or not performing lymph node dissection is probably the most important predictor of lymphocele formation [5]. The extent of lymph node dissection is another risk factor with higher incidences after more extensive dissection [6]. In the current study, with 15 (open) and 13 (robotassisted) procedures, the lymph node yield was higher than in comparable studies $[5,7]$, suggesting an increased risk of lymphocele development. The diagnostic effort made to detect lymphoceles is another important factor that should be taken into consideration. In one study, the lymphocele formation rate was prospectively assessed by pelvic computed tomography after robot-assisted lymph node dissection and radical prostatectomy [7]. In this study, the incidence of lymphoceles was reported to be $51 \%$ [7]. In contrast, in one robot-assisted radical prostatectomy study, lymph node dissection was omitted in low risk patients; therefore, the lymph node dissection rate was only $44 \%$ [8]. In the cited study [8], 95\% of patients were discharged on day 1 and no routine lymphocele screening regimen has been described. Together with the high degree of specialization of the involved surgeon and with recording only symptomatic cases, these facts might have contributed to an extraordinarily low reported rate of $0.36 \%$ symptomatic lymphoceles $[8,9]$. In the current study, lymph node dissection was performed in the vast majority of cases (table 1). Furthermore, according to the recommendations of the German S3 guidelines on diagnostic and treatment of prostate cancer [10], sonographic lymphocele screening was performed. In the case of detection of significant lymphoceles, duplex ultrasound of pelvic vessels was usually obtained and in cases of vein compression or thrombosis, ultrasound-guided drainage and/or surgical fenestration of the lymphoceles were performed. Considering this facts, it is not surprising that the lymphocele rate in this study was in between of the two above-mentioned extreme values [7, 8]. The blood transfusion rates have been reported to be lower in robot-assisted radical prostatectomy than observed in this study $[4,8]$. The relatively high autologous blood transfusion rate after robot-assisted radical prostatectomy in this series was unequivocally attributable to the learning curve of the five involved surgeons who all had no robotic surgical experience other than training in the animal model prior to the start of the program in March 2006. Other surgeons reported similarly high rates during the initial learning curve of robot-assisted radical prostatectomy [11].

During the last 200 robot-assisted procedures, the transfusion rate was only $5 \%$ and it fell to $3 \%$ during the last 100 cases. Compared with the estimated complication rates reported in the guidelines of the European Association of Urology [1], the rates seen in this series (table 2) were within the expected ranges with the exception of a slightly higher rates of lymphoceles that required treatment. This discrepancy may be explained by the above discussed relatively rigorous lymphocele screening and treatment regimen used at our department, the high rate of lymph node dissection and the relatively high number of removed lymph nodes. This study has several limitations. Compared with other studies, the proportion of robot-assisted procedures was relatively small. Therefore, it remains unknown to which degree greater experience and super-specialization would further decrease the complication rates of robot-assisted surgery. The involvement of several surgeons with individual differences in technique and skills may render the demonstration of differences more difficult. Although partially subdivided by the degree of severity, the complications recorded in this database have not been graded according the Clavien-Dindo grading system for the classification of surgical complications [12] that recently gained increasing acceptance in the urological community during recent times [13]. The recording of complications based on chart review by a documentation assistant might have been associated with misclassification or missing of some complications. If it really exists, this problem would, however, affect the open and robot-assisted cohorts at the same degree and it is unlikely that it influenced the results meaningfully. 


\section{Conclusion}

Between open and robot-assisted radical prostatectomy, there were no detectable differences in the incidence of perioperative complications in this study. Since the patient-and tumor-related parameters were more favorable in the robot-assisted subgroup and the transfusion rates fell in the most recent robotic cases, the lack of differences may reflect the learning curves of the robotic surgeons involved in this study.

\section{Acknowledgement}

The authors thank Stefanie Engler for building up the database.

\section{Disclosure Statement}

The authors performed radical prostatectomy with the da Vinci robot (Intuitive Surgical Systems) and attended the console training offered by Intuitive Surgical Systems.

\section{References}

1 Heidenreich A, Bastian PJ, Bellmunt J, Bolla M, Joniau S, Mason MD, Matveev V, Mottet $\mathrm{N}$, van der Kwast TH, Wiegel T, Zattoni F: EAU guidelines on prostate cancer. Update 2012. Available at website: http://www. uroweb.org/gls/pdf/08\%20Prostate\%20Cancer_LR\%20March\%2013th\%2 02012.pdf (accessed: October 4, 2012).

$\checkmark 2$ Moreno Sierra J, Fernández Pérez C, Ortiz Oshiro E, Silmi Moyano A, Villavicencio Mavrich H, Pereira Arias JG, Allona Almagro A, Unda Urzaiz M, Padilla Nieva J, Madina Albisua I, Estebanez Zarranz J, Medina López R, Baena Gonzalez V, Franco Miranda E, Morote Robles J, Gomez Ruiz JJ: Key areas in the learning curve for robotic urological surgery: a Spanish multicentre survey. Urol Int 2011;87:64-69.

3 Shigemura K, Yamanaka N, Yamashita M: Veil nerve-sparing technique and postoperative urinary continence in open antegrade radical prostatectomy. Urol Int 2012;89:283-289.

-4 Novara G, Ficarra V, Rosen RC, Artibani W, Costello A, Eastham JA, Graefen M, Guazzoni G, Shariat SF, Stolzenburg JU, Van Poppel H, Zattoni F, Montorsi F, Mottrie A, Wilson TG: Systematic review and meta-analysis of perioperative outcomes and complications after robot-assisted radical prostatectomy. Eur Urol 2012;62:431-452.
5 Khoder WY, Trottmann M, Buchner A, Stuber A, Hoffmann S, Stief CG, Becker AJ: Risk factors for pelvic lymphoceles post-radical prostatectomy. Int J Urol 2011;18:638-643.

-6 Naselli A, Andreatta R, Introini C, Fontana V, Puppo P: Predictors of symptomatic lymphocele after lymph node excision and radical prostatectomy. Urology 2010;75:630-635.

7 Orvieto MA, Coelho RF, Chauhan S, Palmer KJ, Rocco B, Patel VR: Incidence of lymphoceles after robot-assisted pelvic lymph node dissection. BJU Int 2011;108:1185-1190.

8 Coelho RF, Palmer KJ, Rocco B, Moniz RR, Chauhan S, Orvieto MA, Coughlin G, Patel VR: Early complication rates in a single-surgeon series of 2500 robotic-assisted radical prostatectomies: report applying a standardized grading system. Eur Urol 2010;57:945952.

-9 Wirth MP, Froehner M: Radical prostatectomy-only centers: the future in genitourinary surgery? Eur Urol 2010;57:953-954.
10 Deutsche Gesellschaft für Urologie e.V: Interdisziplinäre Leitlinie der Qualität S3 zur Früherkennung, Diagnose und Therapie der verschiedenen Stadien des Prostatakarzinoms. Version 2.0 - 1. Aktualisierung 2011. Available at website: http://www.awmf.org/ uploads/tx_szleitlinien/043022OLk_S3_ Prostatakarzinom_2011.pdf (accessed October 4, 2012).

11 Artibani W, Fracalanza S, Cavalleri S, Iafrate M, Aragona M, Novara G, Gardiman M, Ficarra V: Learning curve and preliminary experience with da Vinci-assisted laparoscopic radical prostatectomy. Urol Int 2008;80:237244.

12 Dindo D, Demartines N, Clavien PA: Classification of surgical complications: a new proposal with evaluation in a cohort of 6,336 patients and results of a survey. Ann Surg 2004; 240:205-213.

13 Mitropoulos D, Artibani W, Graefen M, Remzi M, Rouprêt M, Truss M, European Association of Urology Guidelines Panel: Reporting and grading of complications after urologic surgical procedures: an ad hoc EAU guidelines panel assessment and recommendations. Eur Urol 2012;61:341-349. 